\title{
Resenha
}

\section{Fundamentação dos Direitos Humanos Desde a Filosofia da Libertação}

\author{
ROSILLO, Alejandro M. Fundamentação dos Direitos Humanos desde \\ a Filosofia da Libertação. Tradução Ivone Fernandes Morcilo Lixa \\ e Lucas Machado Fagundes. Ijuí: Ed. Unijuí, 2015. (Coleção direitos \\ humanos e democracia).
}

Versão original:

ROSILLO, Alejandro M. Fundamentación de Derechos Humanos desde América Latina. México: Itaca, 2013.

\section{Lucas Machado Fagundes}

Doutor e mestre em Direito pela Universidade Federal de Santa Catarina - UFSC. Pesquisador do Núcleo de Pensamento Jurídico Crítico Latino-Americano (coordenador da linha Constitucionalismo Crítico) - Universidade do Extremo Sul Catarinense. Professor do Mestrado em Direitos Humanos e Sociedade da Unesc. Professor convidado do Mestrado em Direitos Humanos da Universidade Autônoma de San Luís de Potosí - UASLP, México. Imachado@unesc.net

\section{Emanuela Gava Caciatori}

Acadêmica de Direito na Universidade do Extremo Sul Catarinense. Pesquisadora de Iniciação Científica do Núcleo de Pensamento Crítico Latino-americano (linha Constitucionalismo Crítico). Monitora da disciplina Teoria do Estado e da Constituição. Estagiária na Defensoria Pública do Estado de Santa Catarina. emanuela_gc@ hotmail.com

\section{Resumo}

0 livro do pesquisador Alejandro Rosillo traduz uma linha de pensamento jurídico crítico, de origem latino-americana, baseando suas reflexões na linha filosófica da libertação e ancorado em três vertentes autorais, no caso Enrique Dussel, Ignácio de Ellacuría e Frantz Hinkelammert. Tal obra objetiva 
abrir um horizonte refletivo em torno da questão que envolve as fundamentações dos direitos humanos, tendo em vista que as tradicionais vertentes jus-naturalista, jus-positivista e pós-moderna, não dão conta da complexidade e da exterioridade que representa o tema no contexto histórico, filosófico e geopolítico regional. Sendo assim, a obra é uma abertura ao pensamento jurídico crítico de matriz "própria", fundamentado nas ideias da filosofia latino-americana para a libertação.

Palavras-chave: Direitos humanos. Alteridade. Libertação. Práxis de libertação. Produção da vida.

\begin{abstract}
The book's researcher Alejandro Rosillo, translates a line of critical legal thinking of Latin American origin, basing their reflections on the philosophical line of liberation, anchored in three copyright aspects in the case of Enrique Dussel, of Ignacio Ellacuría and Frantz Hinkelammert. This objective work open a reflective horizon around the issue involving the foundations of human rights, given that the traditional jus-naturalist aspects, jus-positivist and postmodern, do not account for the complexity and externality that is the subject in the historical, philosophical and regional geopolitical context. Thus, the work is an opening to critical legal thinking "own" matrix, based on the ideas of Latin American philosophy for liberation.
\end{abstract}

Keywords: Human Rights. Otherness. Release. Praxis of Liberation. Production of Life.

\title{
Sumário
}

1 As Fontes Filosóficas do Autor. 1.1 0 Fundamento da Alteridade. 1.2 0 Fundamento Histórico-Social (Práxis de Libertação). 1.3 0 Fundamento da Produção da Vida. 2 Conclusão. 3 Referências. 


\section{AS FONTES FILOSÓFICAS DO AUTOR}

A América Latina é um espaço histórico que foi incluso dentro do projeto chamado modernidade a partir de 1492 e, em termos geoepistêmicos, foi colonizada primeiro pelas matrizes europeias e depois pelas matrizes norte-americanas. Isso redunda em que as ideias sobre os direitos humanos (re)produzidas nessas latitudes sulinas do globo, são fruto hegemonicamente das principais vertentes de fundamentação e interpretação elaboradas no Norte Global (SANTOS, 2009, p. 196). ${ }^{1}$ Logo, o entendimento sobre os Direitos Humanos parte de uma visão histórica recortada no período de 1789 (data da revolução francesa e do surgimento da Declaração dos Direitos do Homem e do Cidadão) como a inauguração da concepção fundamentadora do tema na modernidade, classificando (ou encobrindo) as experiências anteriores como antecedentes históricos, ou seja, invalidando a totalidade das vivências e práticas milenares, inclusive as ocorridas no cenário latino-americano.

Nesse contexto, é possível indagar sobre a possibilidade de uma matriz filosófica e mesmo histórica de sustentação dos direitos humanos na América Latina, afinal a própria ideia de direitos humanos na teoria e na filosofia do Direito remete ao contexto histórico europeu e norte-americano da segunda metade do século 18.

Como, $\mathrm{n}$ entanto, o propósito desta resenha é explorar a temática na área do livro em destaque, ou seja, na teoria e filosofia dos direitos humanos privilegiando o viés crítico, é possível destacar que a historicidade dos direitos humanos e as lutas dos povos no continente se dão logo ao

\footnotetext{
1 Sobre a divisão norte e sul global, destaca Boaventura de Sousa Santos (2009): "El Sur son los pueblos, los países y las naciones que han sufrido más con el desarrollo del capitalismo global, porque se mantuvieron como países subdesarrollados, en desarrollo permanente, sin llegar nunca el marco de los países desarrollados. Y por eso, aprender con el Sur significa que la comprensión del mundo es mucho más amplia que la comprensión occidental del mundo.
} 
início da invasão europeia às terras das denominadas índias. Ora, é logo ao início dos efeitos da conquista espanhola e portuguesa que surgem as primeiras demandas por direitos humanos. O próprio autor, Alejandro Rosillo, demonstra que sujeitos como Bartolomé de Las Casa, Alonso de La Veracruz e Vasco de Quiroga (ROSILLO, 2011) são os pioneiros em relatar e levar à luz da oficialidade as violações e lesões aos Direitos dos povos originários. Cabe destacar que estas circunstâncias são relatos históricos registrados no século 16 , ou seja, dois séculos antes das tendências filosóficas modernas.

Apesar destas referências históricas - que contextualizam o tema -, vale destacar que não é essa a linha teórica de desenvolvimento do pensamento do autor na obra em destaque; isto porque, como o próprio título menciona, trata-se de um livro que objetiva oferecer uma fundamentação para os direitos humanos e dá relevância à Filosofia da Libertação.

Dessa forma, a chamada Filosofia da Libertação trata-se de uma vertente de pensamento que foi desenvolvida no final da década de 60 por pensadores latino-americanos que incorporaram a necessidade de pensar as mazelas socioeconômicas e sociopolíticas desde a realidade histórica do continente. É nesse contexto que se expande nas ciências humanas linhas de pensamento econômico, como a teoria da dependência, pensamento sociológico, como a sociologia da libertação, e mesmo teológico, como a teologia da libertação, ou, então, político, como as lutas pela emancipação.

No presente cenário aparece, em 1977, a obra intitulada "Filosofía de la Liberación” (publicada no México) de autoria do filósofo argentino Enrique Dussel, posteriormente lançada no Brasil (1982); o livro representava não somente a maturidade intelectual deste autor argentino, mas também a sequência do desenvolvimento de ideias pensadas a partir da realidade empobrecida e explorada de Nuestra América. 
Mesmo não sendo a única obra do pensamento liberador, esse livro de Enrique Dussel é um importante marco filosófico para os direitos humanos, como será visto na explicação mais adiante. Juntamente a esta obra, e na mesma linha do discurso de libertação, aparecem, nas décadas de 70 e 80, dois pensadores preocupados com o mesmo cenário de empobrecimento e dominação oligárquica na América Latina: um deles, no contexto da explorada América Central, o teólogo e filósofo espanhol Ignácio de Ellacuría, desenvolve uma prática política dedicada a denunciar e lutar contra os setores sociais dominantes e as força estrangeiras que proporcionam a miséria em El Salvador; já o outro, teólogo e economista de origem alemã, Frantz Hinkelammert, que viveu no Chile na década de 60 e foi um dos intelectuais que trabalhou ativamente no governo de Salvador Allende e também na Universidade do Chile, tendo sua saída do país por conta do golpe militar de Pinochet, radicando-se na Costa Rica.

Apesar das nacionalidades originárias europeias dos dois pensadores destacados anteriormente, ambos se dedicaram e incorporaram a latino-americanidade, pois representam não somente a capacidade intelectiva de produzir filosofia na região, mas que essa filosofia seja pensada e refletida desde as necessidades históricas dos povos daqui, gerando uma condição política para as práticas sociais de direitos humanos.

A partir dessas perspectivas é que aparece a obra do autor mexicano do Estado e da cidade de San Luis de Potosí, Alejandro Martínez Rosillo. O pesquisador é formado em Direito na Universidade Autônoma de San Luis de Potosí (UASLP) e realizou estudos de Mestrado e Doutorado na Universidade Carlos III (UCIII), Madrid, Espanha, tendo se especializado em direitos humanos, com destaque para a sua pesquisa doutoral sobre direitos humanos no contexto histórico latino-americano. Atualmente, o autor coordena um Mestrado em Direitos Humanos na UASLP, e vem dedicando seus trabalhos aos temas que envolvem a perspectiva crítica do Direito sob o viés das Filosofias da Libertação latino-americanas. Em especial, seus estudos têm enfoque histórico, teórico e filosófico no 
sentido da vertente de libertação calcada nas ideias de pensadores como Enrique Dussel e Franz Hinkelammert, com destaque para a Filosofia da realidade histórica e a práxis de libertação no pensamento de Ignácio de Ellacuría (tema da sua Dissertação de Mestrado).

Nesse contexto é que aparece a obra traduzida do espanhol para o idioma português no ano de 2015: Fundamentos dos Direitos Humanos desde a Filosofia da Libertação; publicada pela Editora Unijuí e pelo seu Mestrado em direitos humanos.

Trata-se de um texto que na apresentação feita por Jesús Antonio de la Torre Rangel revela: “[...] a fundamentação que propõe Rosillo não é a que os autores seguem habitualmente, com as correntes da Filosofia do Direito mais aceitas e difundidas, isto é, o iuspositivismo, iusnaturalismo e iusrealismo" (ROSILLO, 2015, p. 9). Por essa razão, o autor mexicano elabora três marcos categoriais que são desenvolvidos e interconectados em cada um dos capítulos: a ideia de alteridade, a práxis de libertação e a ideia da produção da vida, cada um deles correspondendo respectivamente às ideias dos pensadores da libertação anteriormente mencionados. No caso da proposta de Rosillo, as ideias são subsumidas para a leitura da temática dos direitos humanos, sem representar uma mera retórica irreflexiva, como explica o próprio autor:

Nossa pretensão de abordar os direitos humanos a partir da FL não tem como objetivo realizar uma exposição "escolástica" do pensamento de nenhum dos três autores antes mencionados. Buscamos antes utilizar partes de seu pensamento para mostrar como se pode elaborar uma fundamentação dos direitos humanos desde a FL. O que intentamos é outorgar fundamentos filosóficos ao uso dos direitos humanos desde a FL. O que intentamos é outorgar fundamentos filosóficos ao uso dos direitos humanos como ferramentas das vítimas, dos oprimidos e dos pobres em suas lutas de libertação, seguindo os princípios - aprofundando e ampliando-os - que temos revelado na práxis e no discurso dos iniciadores da Tradição Ibero-americana de Direitos Humanos (2015, p. 20). 
Diante disso, a obra representa a possibilidade de reflexão e avanço em outros horizontes nos estudos e nas pesquisas sobre os Direitos Humanos nos inícios do século 21, principalmente pelo fato de buscar outros referenciais que possam explicitar a luta concreta dos povos vitimizados pelas ofensivas globais aos direitos humanos e, principalmente, pelo uso hegemônico e distorcido que fazem algumas ideologias dominantes (como a neoliberal), as quais utilizam o discurso de proteção e promoção de direitos humanos para a prática de violações aos povos periféricos.

Alerta-se, no entanto, que a proposta do livro e do autor não é se tornar um referencial fechado nas ideias exauridas, mas sim obter uma abertura a outras perspectivas interconectadas. Assim, explicita que a “[...] proposta parte da ideia de que não podemos estabelecer um único e absoluto fundamento de direitos humanos, e sim vários dele interconectados entre si” (ROSILLO, 2015, p. 21).

Para realizar esta tarefa, diferentemente dos sujeitos abstratos dos direitos humanos na modernidade, o autor foca em três sujeitos concretos, afinal não existe direitos humanos sem sujeitos de carne e osso. Estes são: a) sujeito intersubjetivo, b) sujeito práxico e c) sujeito vivo, que correspondem ao fundamento da alteridade, da práxis de libertação e da produção da vida, categorias que sustentam a argumentação nos três capítulos da obra.

\subsection{O Fundamento da Alteridade}

O autor dá início à fundamentação de direitos humanos aludindo que estes devem ser baseados desde os sujeitos negados e excluídos da história oficial, uma vez que são os sujeitos concretos que mais precisam da efetividade dos direitos humanos. Aqui não mais se faz alusão ao sujeito típico da modernidade, que é universal, abstrato e a-histórico, mas sim ao sujeito pluriversal, concreto e histórico, que se consolida por meio das 
lutas materiais pelas necessidades da vida. Para tanto, o autor também elege como ponto de referência a realidade de um local geopolítico específico: a América Latina.

O primeiro fundamento de direitos humanos a ser enfrentado por Rosillo é o Fundamento da Alteridade, elemento que foi introduzido na Filosofia da Libertação por Enrique Dussel. A ideia da alteridade surge no sentido de valorizar a subjetividade dos sujeitos, pois se entende como necessária para o processo de libertação, mas sem que isso signifique recair em uma subjetividade abstrata e individualista. Em sentido oposto, para a Filosofia da Libertação a subjetividade do sujeito se constitui no encontro com o Outro; trata-se, pois, de um movimento de reconhecimento d'aqueles sujeitos que não se encontram no centro hegemônico do sistema-mundo. ${ }^{2}$

Enrique Dussel e outros autores assinalam categorias da Filosofia da Libertação que dialogam com o fundamento dos direitos humanos a partir da alteridade: a proximidade, que consiste na aproximação com o outro no sentido de privilegiar as relações humanas; a totalidade, que seria do sistema que engloba todas as coisas, pessoas e objetos que se apresentam ao ser humano, posto que, para Enrique Dussel, a compreensão desse todo se dá com os outros; as mediações, que seria o meio escolhido/ estabelecido para se alcançar o objetivo final da ação; a liberdade situada, que se trata do poder que cabe aos seres humanos de escolher/optar pelas possibilidades reais que se lhe apresentam na materialidade, considerando que disso se depreende que os sujeitos são, ao mesmo tempo, livres e historicamente determinados; e, por fim, a exterioridade, que é a categoria que diferencia a Filosofia da Libertação das demais filosofias produzidas no centro, isso porque é por intermédio desta categoria que se faz possível

2 WALLERSTEIN, Immanuel. Análisis de sistemas-mundo: una introducción. México: Siglo XXI, 2005. 
construir um novo discurso. O Outro, mediante a exterioridade, revela-se não como parte do meu mundo, rompendo com a lógica da igualdade, de reducionismo do Outro ao mesmo e estabelece uma lógica da libertação.

Os direitos humanos, quando não constituídos por meio de uma perspectiva libertária, como é o caso da lógica excludente da modernidade, podem facilmente tornar-se instrumentos de dominação e legitimação de injustiças. Por isso que a Filosofia da Libertação tem como ponto de partida o sujeito que é oprimido e vitimizado; daí emana a ideia do sujeito intersubjetivo, isto é, que não nega a sua subjetividade dos sujeitos, mas compreende que é necessário abrir a pluriculturalidade, a fim de que se possa abarcar como sujeito de direitos humanos todos os indivíduos e não somente aqueles incluídos no sistema da totalidade hegemônica.

Em suma, pode-se sintetizar o fundamento alteridade com as seguintes passagens do autor:

A ética da alteridade busca uma abertura ao sujeito que seja capaz de compreender o novo da história que se constrói a partir da exterioridade: "O ponto de partida é a vítima, o Outro, porém não simplesmente como outra 'pessoa-igual' na comunidade argumentativa, mas ética e inevitavelmente (apoditicamente) como Outro em algum aspecto negado-oprimido (principiumoppressionis) e afetado-excluído (principiumexclusiones)." A partir do outro - o pobre, o oprimido, a vítima - que é a liberdade incondicionada enquanto é desprezada sua exterioridade considerando-a nada (como não cultura, analfabetismo, barbárie, primitivismo, não civilizado), é como surge a história do novo. Por isso todo sistema futuro que resulte realmente de uma revolução subversiva no sentido metafísico é analógica: semelhante em algo a anterior totalidade, porém realmente distinto (ROSILLO, 2015, p. 68).

Logo, a alteridade, quando contextualizada e retirada do discurso formal dos direitos humanos, assume um caráter transformador:

[...] direitos humanos fundamentados a partir da alteridade devem ser compreendidos como ferramentas de luta dos que são vítimas do sistema e por esta razão, mais que elementos conservadores do sistema, 
devem ser subversivos, transformadores e revolucionários. $\mathrm{O}$ face a face com o outro inequívoco obriga a repensar constantemente direitos humanos, pois direitos humanos não são parte do sistema (ROSILLO, 2015, p. 68).

A FL parte da premissa de que é equivocado viver forma individual, que nossa completude enquanto seres humanos se dá no face a face, no reconhecimento do/e para com o Outro. Afinal, viver em comu(m)nidade é a única forma possível de produzir a vida, por isso os direitos humanos devem fundamentar-se não no indivíduo isolado, mas sim na intersubjetivade. Ademais, assinala-se que a alteridade não é o único fundamento dos direitos humanos, conquanto não há um fundamento absoluto.

\subsection{O Fundamento Histórico-Social (Práxis de Libertação)}

$\mathrm{Na}$ abordagem do fundamento histórico-social, Rosillo inicia assinalando que a Filosofia da Libertação também deve ser compreendida como uma filosofia da práxis, contudo é necessário salientar que nem toda práxis é libertadora, uma vez que existem as que podem ser consideradas excludentes, alienantes, etc. Disso depreende-se que os direitos humanos podem tanto ser produto de uma práxis ideologizadora e opressora quanto de uma práxis de libertação.

Nesta senda, o autor mexicano utiliza o pensamento de Ignácio Ellacuría para inserir o fundamento histórico-social como base dos direitos humanos. A práxis da libertação é um elemento que não se opõe à ideia de alteridade, mas a complementa, posto que pode ser traduzida como as lutas que os sujeitos vitimizados empreendem para que superem a dominação à qual estão submetidos.

Ellacuría fundamenta a práxis a partir da análise de um todo que integra a realidade histórica desde o indivíduo até a sociedade. A ideia de história, para o autor, é que esta não se apresenta como um resultado findo, que está no passado e já é determinado, mas como algo passível de 
análise e que se inova constantemente, sendo um processo contínuo. A história é, pois, um movimento de criação de possibilidades reais ante a materialidade.

Para uma compreensão historicista, é imprescindível assinalar que existem forças históricas que independem da ação dos indivíduos, mas que, igualmente, influenciam nos processos históricos. Mesmo que a vontade humana tenha direta relação com a marcha histórica, ela, por si, não é determinante sozinha. Isso afasta a ideia individualista de que a simples mudança de comportamento pessoal seria capaz de transformar um conjunto social.

A realidade histórica é um movimento empreendedor que comporta um dinamismo que é devir, isto é, não é a mudança concreta, per si, mas um movimento de transformação. Esse dinamismo apresenta as possibilidades do ser e o vai forjando e formando a partir das possibilidades concretas existentes. Esse movimento presente na história assume a forma de práxis enquanto criador de possibilidades e capacidades.

Ellacuría assinala que a práxis é a interação entre os seres humanos e o mundo, estabelecendo que ela não é toda atividade humana, mas apenas aquela transformadora e real; justamente por isso é que o autor argumenta que a práxis afeta a totalidade da vida humana por seu potencial transformador. Também se torna impossível dissociar a teoria da práxis. Ellacuría reconhece aquela enquanto o momento intelectual da práxis e insere a reflexão sobre a práxis histórica como tarefa da Filosofia da Libertação. É necessário, pois, inserir a Filosofia dentro das lutas pela libertação e refletir sobre a práxis histórica enquanto práxis libertadora.

A realidade histórica é entendida como um processo de libertação gradual. A libertação se realiza a partir da materialidade concreta, embora a liberdade em abstrato não é realizável; o indivíduo faz-se livre ao optar por coisas reais dentre uma gama de possibilidades que se apresenta na realidade. Aqui se dá ênfase a práxis histórica de libertação, pois 
é nesta que se enxerga a capacidade de edificar novas estruturas capazes de melhorar concretamente as vidas humanas, partindo-se sempre dos sujeitos negados e oprimidos como referencial. Aliás, a práxis da libertação ocorre em processo dialético, pois consiste em negar a negação dos indivíduos em um intento de afirmar-lhes as condições reais de vida.

Ressalta-se, contudo, que a realidade histórica pode tanto ser libertadora quanto opressora e excludente. Entender a libertação como um processo é necessário para que se almeje a mesma sem recair em idealismo e conceitos abstratos.

Quanto ao processo de libertação, o autor assinala:

A libertação é, então, um processo através do qual o ser humano vai exercendo sua liberdade, e vai tornando-se cada vez mais livre graças a sua estrutura de essência aberta: "A libertação é, portanto, um processo. Um processo que, na dimensão pessoal, é, fundamentalmente, um processo de conversação e que, no histórico, é um processo de transformação, quando não de revolução" (ELLACURÍA apud ROSILLO, 2015, p. 86).

O caminho da libertação consiste em o ser humano tornar-se dono de seu próprio destino e reivindicar para si seu processo de transformação. Um processo real de libertação, no entanto, deve abarcar todos os seres humanos e não somente aqueles inseridos na totalidade hegemônica da modernidade, por isso esse processo supõe também luta pela justiça. A Filosofia da Libertação não pretende negar as liberdades individuais, mas compreender e denunciar sua limitação, posto que o processo do qual teve origem não foi capaz de conceder a libertação para a ampla parcela não privilegiada da sociedade. A Filosofia da Libertação intenta fomentar um processo de libertação que esteja mais em contato com a materialidade e a realidade histórica, e que seja mais universal. 
Destarte, para a Filosofia da Libertação o paradigma e o fundamento da libertação não é o mesmo em diferentes momentos e contextos históricos. Rechaça-se a ideia moderna de elencar um único fundamento e elegê-lo como imutável e válido em todos os tempos e espaços. A libertação pressupõe materialidade e universalidade, no entanto é preciso cautela para que não se construa um universalismo abstrato e totalizante; é necessário compreender a pluralidade das realidades históricas e as condições materiais dos diversos povos que formam a humanidade, por isso a FL considera insuficiente a construção de uma fundamentação de direitos humanos de forma absoluta e dogmática.

Parte-se da premissa de que o fundamento dos direitos humanos cabível para a Filosofia da Libertação teria como motor a luta social em matrizes histórico sociais (ROSSILO, 2015, p. 91). Trata-se, portanto, de um fundamento mais de cunho sociológico do que filosófico, chamado fundamento histórico-social.

O objeto e também ponto de partida da Filosofia da Libertação é o sujeito da práxis da libertação, que é o débil, a vítima, o marginalizado, não privilegiado e excluído, que não é constituído mediante uma acepção subjetiva individual, mas por meio de uma intersubjetividade, o que significa dizer que a Filosofia da Libertação reconhece a concretude da subjetividade de cada indivíduo humano e a importância de seu encontro com o outro, da alteridade, para o processo de libertação. O sujeito vitimizado constitui-se enquanto sujeito da práxis ao perceber-se dominado pelo sistema que causa a vitimização, em um processo que requer a tomada de consciência da opressão seguida pela elaboração de uma crítica ao sistema vigente.

Tendo em vista que a realidade histórica não é finda e está em constante mutação, a crítica ao sistema é sempre necessária, uma vez que é preciso se ter em mente que é impossível construir um sistema perfeito em que não haja nenhuma vitimização ou estrutura excludente. As novas opressões vão surgindo conforme o progresso da marcha histórica, 
devendo ser percebidas conforme seu surgimento, posto que é impossível prever todas as possibilidades existentes no sistema-mundo, sendo sempre passíveis de críticas e problematizações a fim de que se dê continuidade ao processo de libertação. Essa compreensão significa tão somente entender que a realidade histórica é dinâmica.

Por fim, pode-se se sintetizar a práxis da libertação como um dos fundamentos dos direitos humanos que tem como intenção a subversão de um sistema que vitimiza e oprime para que se possa construir um novo sistema, em que seja possível a produção e a reprodução de vida de todos os sujeitos humanos, por meio da satisfação das necessidades materiais para tanto.

\subsection{O Fundamento da Produção da Vida}

O terceiro pilar da obra de Rosillo, apresentado no capítulo quatro, é o último fundamento elencado da proposta crítica dos direitos humanos: o fundamento da produção da vida. Para tanto, toma como ponto de partida a premissa de que o "sujeito vivo" é o tema central da reflexão da Filosofia da Libertação. O sujeito da Filosofia da Libertação, portanto, é uma espécie de sujeito trifásico, que é, ao mesmo tempo, sujeito vivo, intersubjetivo e da práxis da libertação.

O autor desenvolve que:

A FL tem como um tema central de sua reflexão ao "sujeito vivo", e em conexa com ele à satisfação das necessidades para a vida. A recuperação do sujeito não só é referida a um sujeito intersubjetivo e a um sujeito da práxis de libertação, mas também ao sujeito como sujeito vivo, como um ser corporal, pelo qual a satisfação de necessidade se constitui como um feito radical. Isto não quer dizer que o sujeito intersubjetivo e o sujeito da práxis fiquem relegados a um segundo sitio, outorgando-lhes a primazia ao sujeito vivo. Não se trata de hierarquizar aos "sujeitos", e sim que falamos de um "sujeito trifásico", por dizer de alguma forma; um sujeito que é parte da fundamentação dos direitos 
humanos desde o pensamento da libertação. Assim, para que o sujeito de direitos humanos realmente seja tal, deve ser simultaneamente um sujeito vivo, intersubjetivo e práxico. A ausência de qualquer deles, ou a ausência total de sujeito, significaria que a fundamentação dos direitos humanos cairia em algum dos riscos analisados no capítulo primeiro (ROSILLO, 2015, p. 105).

Para a análise desse fundamento, Rosillo estabelece o pensamento de Frantz Hinkelammert como marco teórico. Na Filosofia da Libertação o sujeito vivo é aquele que se constitui diante das necessidades concretas para a satisfação da vida. Rechaça, pois, o sujeito moderno, uma vez que este é abstrato, mas sem cair na negação pós-moderna da subjetividade. Trata-se, portanto, de um sujeito real, vivo, que tem exigências reais e materiais para a satisfação concreta de suas necessidades. É um sujeito em contato com a realidade histórica, que se reconhece na alteridade do outro.

O marco material da práxis do sujeito vivo é a satisfação das necessidades para a vida dos sujeitos vitimizados e excluídos. Hinkelammert desenvolve seu pensamento ao assinalar que a racionalidade moderna nega os direitos humanos ao se impor enquanto racionalidade que se supõe universal, quando, na verdade, é apenas a racionalidade hegemônica. Essa racionalidade fundada na Modernidade se fundamenta em um viés economicista que eleva a economia e a competitividade como valores máximos em detrimento dos demais. Por meio dessa lógica é conferido valor e utilidade na sociedade, o que pode ser alvo de competição. Isso é prejudicial para os sujeitos concretos na medida em que leva à negação de qualquer indivíduo que esteja à margem dessa hegemonia competitiva. Traça-se um horizonte totalitário, encobrindo e excluindo quaisquer outras culturas, povos e sujeitos que não se enquadrem na lógica da competitividade. A racionalidade meio-fim, típica da modernidade, elege o eficientismo e a competitividade como valores últimos que conferem validade ou não aos demais valores, diminuindo a importância para a consequência dessas ações na vida prática dos sujeitos. 
$\mathrm{Na}$ contramão da racionalidade meio-fim, Hinkelammert contribui com a ideia de uma racionalidade reprodutiva, que consiste na postulação de que a vida do sujeito-ator não pode ser meramente um fim. O sujeito transforma-se em ator no momento em que reflete sobre suas ações e toma as rédeas da consciência da própria vida. Nesse novo tipo de racionalidade o sujeito encontra-se no centro do pensamento, que é a racionalidade meio-fim, porque não parte do juízo de eficiência, mas de uma racionalidade circular que insere a vida do ator no meio da ação; é realizado um juízo de possibilidades em que se verificam os resultados concretos destas ações na vida do sujeito. A emergência dessa outra racionalidade se faz necessária na medida em que responde a uma exigência material do ser humano perante a realidade histórica, isto é, a de manter-se vivo e ser capaz de produzir e reproduzir sua vida. Ignorá-la seria um aval para reproduzir a morte dos indivíduos, não obstante a racionalidade meio-fim não abarca a preocupação com a vida dos atores enquanto elemento essencial.

O sujeito vivo deve ser o sujeito da práxis da libertação, que tem como objetivo central a satisfação material das necessidades das vítimas e a transformação do sistema a fim de que se crie um outro modelo que produza e reproduza a vida. A tomada de consciência das vítimas do sistema consiste em percebê-lo enquanto gerador de mortes e enfrentá-lo a fim de construir uma racionalidade e um sistema diferentes. Nesse processo há o princípio formal, que consiste na tomada de consciência por parte das vítimas, que se organizam e entram em um consenso, e o princípio material, que se traduz no desenvolvimento das condições materiais de vida.

Há uma relação patente entre o sujeito vivo e a intersubjetividade, na medida em que a afirmação da sua própria vida, enquanto exigência do sujeito vivo pelas condições materiais para gerar vida, também se dá na intersubjetividade, ao passo que a afirmação da vida se complementa com a afirmação e o reconhecimento da vida do Outro. 
O sistema hegemônico da modernidade nega a produção e a reprodução da vida de muitos sujeitos, o que imperativamente deve a Filosofia da Libertação defender. O fundamento da produção da vida é, pois, um fundamento mais objetivo e materialista, pois visa à satisfação das necessidades concretas dos sujeitos vivos. Apesar de essencial, a produção da vida não deve ser elencada como fundamento único de direitos humanos, pois isso poderia redundar em uma visão individualista e egoísta. A libertação, por sua vez, precisa dar-se no âmbito da solidariedade, por isso as concepções individualistas não são úteis para a Filosofia da Libertação.

\section{CONCLUSÃO}

Construir uma fundamentação de direitos humanos a partir da Filosofia da Libertação não se trata de meramente criticar a modernidade e a fundamentação hegemônica dos direitos humanos, mas sim apontar possíveis caminhos a se seguir para que se torne possível construir uma lógica libertária, na qual os direitos humanos sejam utilizados enquanto instrumentos de libertação dos povos oprimidos por meio das lutas concretas. Para além de uma fundamentação historicista dos direitos humanos, trata-se de elaborar uma fundamentação propositiva.

Mediante a Filosofia da Libertação, e partindo da América Latina enquanto espaço geopolítico, é possível estabelecer três fundamentos - a alteridade, a práxis da libertação e a produção de vida - enquanto elementos que devem estar juntos, de forma interseccional, para que os direitos humanos possam ser utilizados enquanto instrumento de libertação. Os direitos humanos devem ser ferramentas de luta para que os sujeitos oprimidos, as vítimas e os débeis deixem de sê-lo e tornem-se libertos das opressões do sistema, e é justamente esse objetivo que a Filosofia da Libertação intenta concretizar. 
A América Latina nasceu da pioneira hecatombe da modernidade - a colonização/colonialidade -, e foi erigida em constantes atos de desumanização fundamentados nas mais sofisticadas elaborações filosóficas, teóricas e históricas validadas por discursos e documentos jurídicos formais. Na exterioridade destes processos, contudo, sempre apresentaram-se sujeitos vivos lutando a partir da sua condição de injustiçados e por compreender que a injustiça não é uma normalidade.

É, portanto, na recuperação das lutas e na insurgência crítica à condição material em que vivem historicamente, que aparecem outras fundamentações de direitos humanos ligadas à condição concreta de sujeitos vivos e historicamente localizados.

\section{REFERÊNCIAS}

DUSSEL, Enrique. Filosofía de la Liberación. México: Edicol, 1977.

ROSILLO, Alejandro. Fundamentação dos Direitos Humanos desde a Filosofia da Libertação. Tradução Ivone Fernandes Morcilo Lixa e Lucas Machado Fagundes. Ijuí: Editora Unijuí, 2015. (Coleção direitos humanos e democracia). Fundamentación de derechos humanos desde América Latina. México: Editorial Itaca, 2013. (Versão original).

. Los inicios de la tradición iberoamericana de derechos humanos. San Luis Potosí/Aguascalientes, México: Universidad Autónoma de San Luis de Potosí; Centro de Estudios Jurídicos y Sociales Mispat, 2011.

SANTOS, Boaventura de S. Pensar el Estado y la sociedad: desafíos actuales. Buenos Aires: Waldhuter, 2009.

WALLERSTEIN, Immanuel. Análisis de sistemas-mundo: una introducción. México: Siglo XXI, 2005.

Recebido em: 20/1/2017

Aceito em: 21/1/2017 